\title{
A NEW METHOD FOR ASSESSING COMPATIBILITY OF CONSOLIDATION PROCEDURES WITH CONSERVATION PRINCIPLES: INTERVENTION QUALITY INDEX (IQI)
}

\section{NURIA CHIARA PALAZZI ${ }^{1,2 *}$, GIULIA MISSERI ${ }^{3}$, CRISTIÁN SANDOVAL ${ }^{2}$, UGO TONIETTI $^{3}$, JUAN CARLOS DE LA LLERA ${ }^{1,2}$ AND LUISA ROVERO $^{3}$}

\author{
${ }^{1}$ Research Center for Integrated Disaster Risk Management (CIGIDEN), ANID/FONDAP/15110017 \\ e-mail: nuriachiara.palazzi@ cigiden.cl(*corresponding author) \\ ${ }^{2}$ Pontificia Univesidad Catolica de Chile \\ Avda. Vicuña Mackenna 4860, Macul, Santiago, Chile \\ email: jcllera@ing.puc.cl, and csandoval@ing.puc.cl \\ ${ }^{3}$ Department of Architecture, University of Florence \\ Piazza Brunelleschi, 6, 50121, Firenze, Italy \\ email: giulia.misseri@unifi.it, u.tonietti@unifi.it, luisa.rovero@unifi.it
}

Keywords: Built heritage, Masonry, ICOMOS principles, Retrofit interventions

\begin{abstract}
In current times, built heritage is being lost at an alarming rate due to natural and human hazards. Policies for its protection and rehabilitation involve, among other things, challenges related to the refinement of suitable structural strengthening approaches. The arduous balance between gaining acceptable safety levels for occupants without deploying intrusive devices, inconsistent with conservation principles such as those of the ICOMOS charters, is not a simple task. The interest and efforts of the scientific community in this regard have been increasing for decades, but still, it is the structural professional's responsibility and experience which must define this arduous balance on a case-to-case basis.
\end{abstract}

This study addresses the question: How can the quality of structural rehabilitation interventions be assessed in light of conservation principles such as those given by ICOMOS? Here, a preliminary method - called "Intervention Quality Index" (IQI) method is proposed. It assesses the restoration intervention quality in relation to: (i) the level of compliance given by the conservation's principle score (conservation's factor, CF); and (ii) the current state of conservation of the monument (safety factor of building considering the seismic intensity, $\Delta_{s}$ ). The IQI method considers the compliance level of the designed reinforcement with conservation principle, formalized through the fulfillment of a category, i.e. respected, partially respected, and not respected. Then, these judgments are translated into scores and statistically evaluated. Scores are attributed in relation to the relevance of the fulfillment of a certain conservation principle (authenticity, minimal intervention and intrusiveness, compatibility, recognizability and reversibility) for the seismic structural safety point of view. Preliminary results show that an effective employment of traditional earthquake-resistant practices together with a wise use of modern retrofit strategies allow for the preservation and reinforcement of built heritage without harming its identity. 


\section{INTRODUCTION}

From recent studies of the seismic fragility assessment at macro-scale and singlebuilding-scale of Built heritage [1], [2], [3], [4], [5], and [6], it emerged that several URM monuments, in particular churches, even those consolidated and repaired after a seismic event, demonstrated inadequate performance during sequent ones.

For this reason, several investigations were carried out to develop guidelines and standards for repairing, consolidating and strengthening URM built heritage while respecting ICOMOS conservation philosophy. New Zealand's Building Seismic Performance of existing structures [7], the Building Code Requirements for Masonry Structures by the American Society of Civil Engineers [8], the National Peruvian Building Code for earthen structures [9], the section Retrofit Design Procedure for existing building of the European code for Design of structures for earthquake resistance [10], the Italian Code NTC2008 [11] and Circ.26/2010 [12], and the Chilean Standard for the Structural Intervention of Earthen Historical Buildings [13], are some of the outcomes of thisresearchin some of the world's most earthquake-prone countries, in which criteria for strenthening interventions is provided.

Another set of guidelines for conservation and repair of heritage buildings are the Guidelines for earthquake resistant non-engineered construction published by UNESCO [14], and Principles for the analysis, conservation and structural restoration of architectural heritage [15]. These guidelines present a set of criteria to assess damage types and levels, correlating post-seismic scenarios to possible traditional and modern repair and strengthening techniques

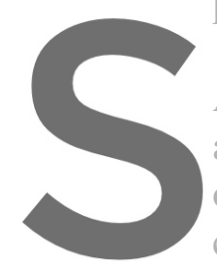
Although the interest of the scientific community toward this task have been increasing, the
arduous balance between achieving acceptable safety levels for occupants without deploying
overly intrusive devices, inconsistent with conservation principles such as those of ICOMOS
charters, has yet to be resolved. To this aim, a preliminary method ealled the Interyention Quality Index (IQI) method is proposed.

Register for free at https//www.scipedia.com to dowṇload the version without the watermark The paper is organized as follows. After summarising the set of fundamental conservation principles within the framework of structural consolidation interventions, the preliminaly IQI method is presented in Section2. In Section3, stability and strength-based techniques for the reduction of seismic vulnerability of monumental buildings are analyzed through the IQI method which considers the compliance level of each conservation principle.

Then, two case studies on reinforcement interventions are addressed in Section4: the buttresses for improve the stability of San Francisco church's transept walls [16], and the tierods for retaining the thrust of external gallery arches of Basilica del Salvador [17]. Both interventions are analyzed through IQI method. Preliminary conclusions are drawn in Section5.

\section{ICOMOS PRINCIPLES AND INTERVENTION QUALITY INDEX METHOD}

The conservation philosophy has a direct consequence on seismic retrofit projects. The most universal principles of conservation are: authenticity, minimal intervention and intrusiveness, compatibility, recognizability, and reversibility, [18] and [19]. In the following, 
the conservation criteria are stated analyzing the effect that complying with them has on the structural behavior induced by a reinforcement system:

- Authenticity $[\mathrm{Au}]$ of the original features of the building (materials, geometry), which must be preserved "ensuring that the original mechanical and resisting principles governing the structure response are not altered and original structural elements are not made redundant" [4];

- Minimal intervention and intrusiveness [Mi], which consist of an intervention where the human safety and conservation requirements are balanced, througth a cost-benefit analysis that also includes intangible value losses;

- Compatibility $[\mathrm{Co}]$ between new retrofitting materials and existing elements is related to chemical, physical and mechanical properties. The retrofits and structural elements "not only do no harm to the original ones, but they also act as sacrifical elements in precence of external actions, i.e. they should act as fuses of the structural system" [4].

Furthermore, the constructive compatibility allows for reduction of structural discontinuities, which are the preferencial ways of damage in case of seismic motion, and guarantees integration among structural elements and a greater level of monolithicity of masonry walls;

- Recognizability $[\mathrm{Rc}]$ of retrofitting interventions allows to easily detect the original constructive systems of the building and also possible structural heterogeneities due to post-earthquake repairs (main vulnerability feature in URM structures subject to
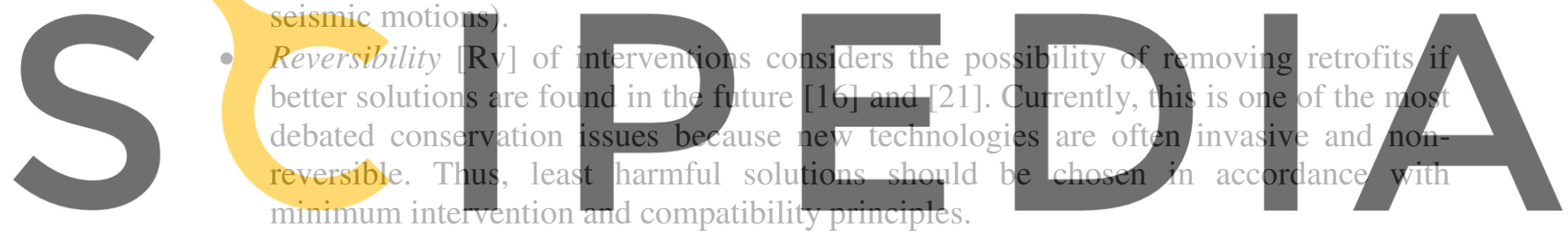

In order to assess the analyzed retrofitting technique/intervention, the degree of agreement

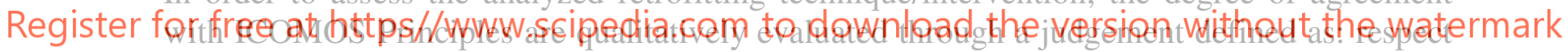

(R), partial respect (PR), and no respect (NR), Table1. These judgement categories (JCs) are directiy related to the performance levels (PLs) based on experts' judgment, Table1. Based on the assessment of the fullfilment level between the analyzed intervention and the ICOMOS Principles, a numerical score is assigned to each judgement category. The numerical scores associated with the judgement presented in Table1, are used to evaluate the Intervention Quality Index (IQI) which turns out to provide the level of comformity of new intervention with ICOMOS philosophy. The IQI index is computed by the following equation:

$$
\mathrm{IQI}=\Delta_{\mathrm{Is}} \cdot C F
$$

Where, $\Delta_{\mathrm{Is}}$ is the safety index increment and CF is the conservation factor, given respectively by the following expressions:

$$
\Delta_{\mathrm{Is}}=\mathrm{I}_{\mathrm{s} 2}-\mathrm{I}_{\mathrm{s} 1} \quad \text { (2); } \quad \text { and } \quad C F=\sum_{\mathrm{k}=1}^{\mathrm{N}} \hat{\gamma}_{\mathrm{PI}_{\mathrm{k}}}=\sum_{\mathrm{k}=1}^{\mathrm{N}} \frac{\gamma_{\mathrm{PI}_{\mathrm{k}}}}{\gamma_{\mathrm{PI}_{\mathrm{k}, \max }}}
$$

Where, $\mathrm{I}_{\mathrm{s} 1}$ and $\mathrm{I}_{\mathrm{s} 2}$ are the safety indexes of the structure before and afterthe intervention, respectively, each obtained as the ratio between spectral seismic acceleration capacity and seismic acceleration demand. 
In the conservation factor $C F, N$ is the number of considered ICOMOS principles (PI), which are $\mathrm{Au}, \mathrm{Mi}, \mathrm{Co}, \mathrm{Re}$, and $\mathrm{Rev}$, and $\gamma_{\mathrm{PI}_{\mathrm{k}}}$ is the $k$-th score, which can range between 0 and 3 according to the judgment category for each considered ICOMOS principle $\left(P I_{k}\right)$. Table1 resports the definition for each conservation principle and the associated score for each judgement. The value of the conservation factor $C F$ is thus obtained as the sum of normalized scores, $\hat{\gamma}_{\mathrm{PI}_{\mathrm{k}}}$; normalization of $\gamma_{\mathrm{PI}_{\mathrm{k}}}$ is considered with respect to the corresponding maximum possible score, in this case with $\sum_{\mathrm{k}=1}^{\mathrm{N}} \gamma_{\mathrm{PI}_{\mathrm{k}, \max }}=12$ since all five PIs are considered.

Table 1: ICOMOS principle ID, judgement category (JC), conservation's principle score $\left(\gamma_{P_{k}}\right)$ given to each $\mathrm{JC}$, and description for each conservation principlesof performance levels.

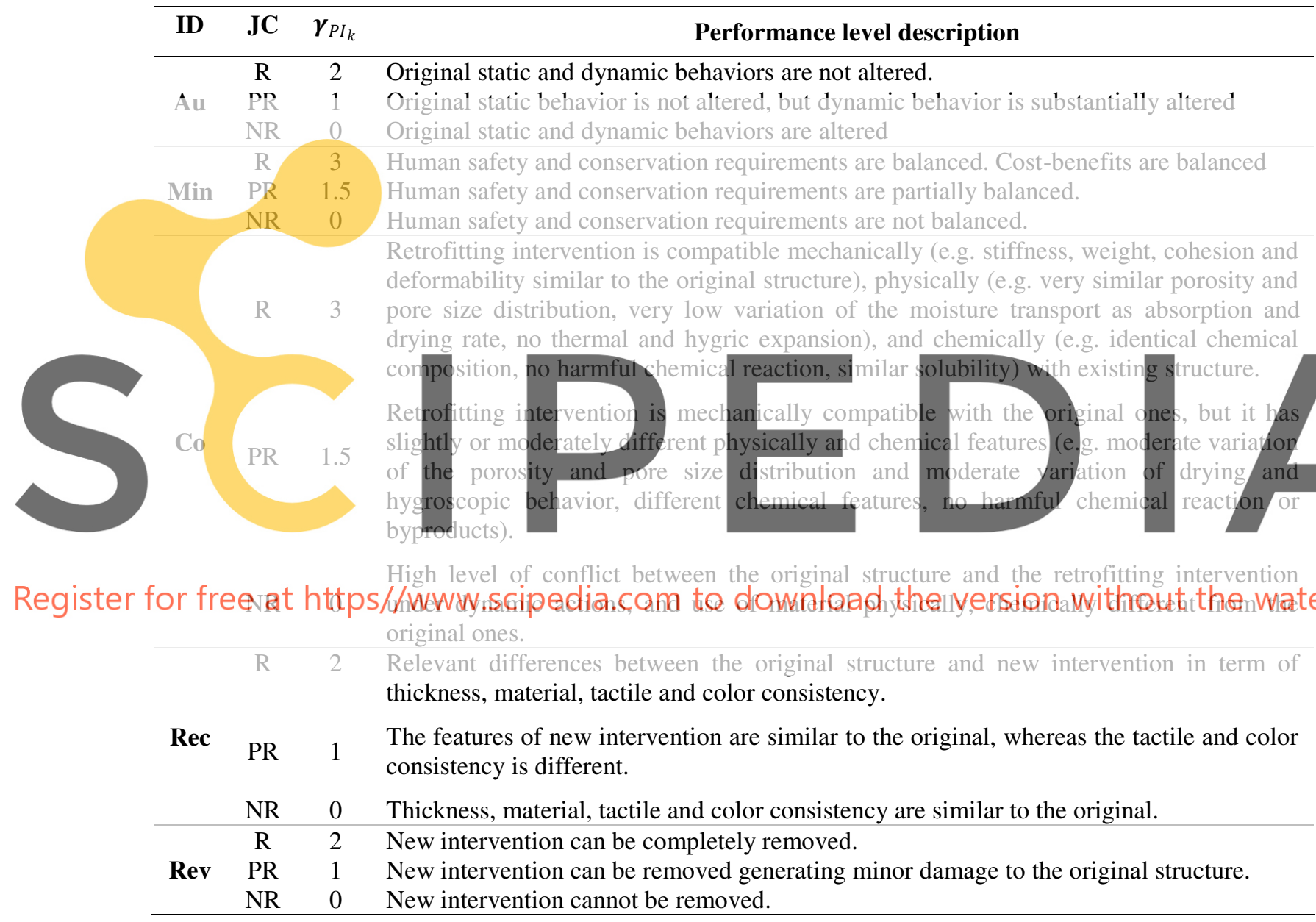

To calculate seismic capacity and demand in the case of stability-based techniques, local analyses by damage mechanisms through limit analysis with kinematic approach are suggested (according to [11], [12] and [13]). While to assess the safety indexes before and after a strength-based intervention, which often involves wide areas of the structure, targeted global analyses are recommended.

Based on the value obtained for the IQI index, four categories of fulfillment are defined in the framework of the safety assessment against local damage mechanism 
triggering, as shown in Table2: Category A, the intervention meets fully safety requirements and guarantees full compliance with the conservation principles; Category $\mathrm{B}$, the intervention meets partially safety requirements (improvement) and guarantees compliance with the conservation principles; Category $\mathrm{C}$, the intervention meets meets safety requiremts (either fully or partially)but does not guarantee complete compliance with the conservation principles; Category D, the intervention does not meet safety requirements and does not guarantee compliance with the conservation principles.

Table 2: Intervention conformity level to ICOMOS principles

\begin{tabular}{cccc}
\hline \multicolumn{4}{c}{ Intervention conformity level } \\
\hline $\mathbf{A}$ & $\mathbf{B}$ & $\mathbf{C}$ & $\mathbf{D}$ \\
\hline $0.75<\mathrm{IQI} \leq 1$ & $0.5<\mathrm{IQ} \mathrm{I} \leq 0.75$ & $0.25<\mathrm{IQI} \leq 0.5$ & $0<\mathrm{IQI} \leq 0.25$ \\
\hline
\end{tabular}

A state of poor conservation of the materials in the structure (i.e. degradation of materials due to continuous exposure to the elements which generates degradation phenomena reducing structural efficiency), the presence of poor quality materials (i.e. irregular textures and/or incoherent and friable mortar), and design errors in the original structure (i.e. lack of wall-towall and wall-to-roof connections, excessive slenderness, wall pattern not respectful of the rule-of-the-art etc) inevitably require invasive and consolidation projects which depart from ICOMOS principles. In these cases, the priority is to guarantee the minimum safety level. Therefore, it is necessary to evaluate the invasiveness of the project considering the initial conservation state of the building, and related with the required safety level to the ICOMOS

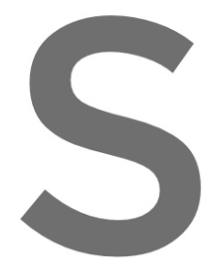
principles. In particular, minimally invasive required. The Internation this issue, and for recommendations. Thus, ICOMOS princip
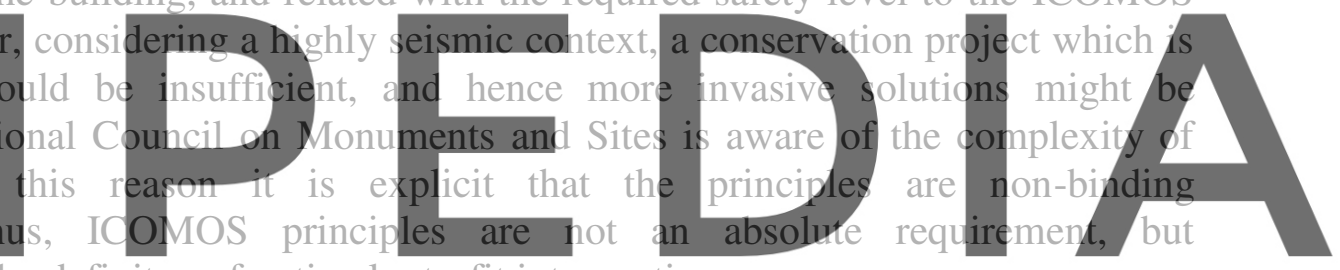

recommendations for the definiton of optimal retrofit interventions.

Register for free at httas fow INTERVENTION

The passage from the analytical-diagnostic phases to the intervention project consists of designing a unified intervention strategy considering the identified vulnerabilities and structural deficiencies. The main goals of an anti-seismic reinforcement intervention project are to prevent the activation of local collapse mechanisms both in-plane and out-of-plane, and to guarantee box-like behavior while respecting conservation philosophy. The design improvement devices must be able to: (i) collaborate with existing elements and contrast local vulnerability; (ii) systematically increase the displacement capacity of the structure, admitting partial deformations and cracks; (iii) restore the structural resistance of the initial system; (iv) avoid introducing concentrated and relevant stiffness (R.C. slab and injections etc.); and (v) increase the tensile resistant connections.

In [21] two main classes of complementary retrofitting interventions are distinguished: (I) Stability-based techniques, which reduce the deficit connections and thrust of arches and vaults; and (II) Strength-based techniques, which restore and increase the resistance of masonry wall. 


\subsection{Stability-based techniques}

The stability-based techniques reduce deficiency between connections and thrust of structural elements (arches, vaults etc.), stabilizing the structure as a whole, in order to increment box-like-behavior. Common stability-based techniques for URM buildings are:

(i) Steel tie-rod/cross-bracing [TR- CB], widely used in historical structures to connect wallto-wall and wall-to-floor and to improve the building integrity; (ii) Wooden ring-beam [RB], placed on top of the walls to guarantee box-like behavior and prevent the activation of out-ofplane mechanisms, providing strength and stiffness against bending; (iii) Brick-masonry enlargement [EN], consisting of a new massive local masonry addition in order to increase the wall section and prevent out-of-plane failures; (iv) Brick-masonry buttresses [BT], generally involving the entire length of the wall and supporting the wall corner and/or projecting from the section of an internal transverse wall, providing resistance to lateral thrusts.

Table 3 - Stability-bases techniques

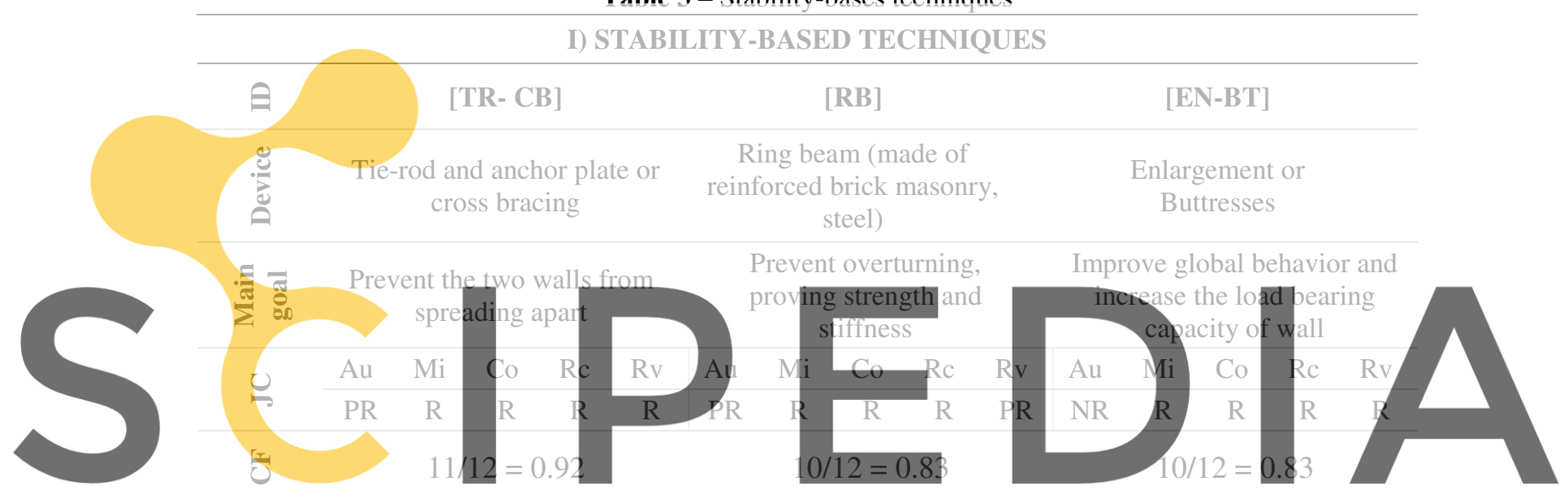

Register for poliminary valiqgtion of the Id method is carried out assessing each mentioned thability wermark based technique. Firstly, a qualitative judgment on total, partial or absence of the respect of conservation principles is provided in Table3. Then, the numerical scores associated with the

JCs are used in Equ. (3) to calculate $C F$, shown in Table3.

The analyzed stability-based solutions show a high compliance level of each conservation principle $(\mathrm{CFs}=0.83-0.91)$. The implementation of restoration solutions using traditional materials (steel TR-CB, wooden RB, masonry EN-BT) is advantageous from a cost and compatibility point of view. However, in highly seismic regions these materials could be insufficient and modern devices might be employed such as systems based on fiber-reinforced composite materials or reinforced-brick-masonry, among others.

\subsection{Strength-based techniques}

Strength-based techniques improve the strength of walls by providing better "monolithic" behavior to masonry. Common strength-based techniques for URM structures are:

(i) Unstitch-stitch intervention [US], consisting of dismantling and rebuilding a portion of a cracked wall, with the aim of restoring continuity and structural integrity; (ii) bed joint repointing [BJR], replacing bad joint mortars with better quality ones; (iii) grout injection [GI], largely applied to fill the holes, cavities and internal voids to reconstitute the structural 
continuity and increase the mechanical properties of masonry walls; (iv) artificial headers $[\mathrm{AH}]$, which provide transversal locking in wall thickness, connecting the adjacent wall leaves, increasing the monolithicity of masonry panels and the global behavior of structures as well as; (v) Jacketing of masonry [JM]consisting in the use of steel or different fiber, such as CFRP or inorganic matrix, placed on both wall faces and connected thought transversal elements that cross the wall section; (vi) confinement of columns and pillars with composite or steel materials $[\mathrm{CN}]$, located in critical sections of vertical elements, generally in the lower part of shafts where vertical cracks are present, to contain transversal dilatation and improve stability of columns and pillar. Also in the case of strength-based techniques, a preliminary validation of the IQI method is carried out. A qualitative judgment regarding the respect of conservation principles is provided in Table4, together with the $C F$ values for each mentioned strength solutions.

Table 4: Strength-bases techniques

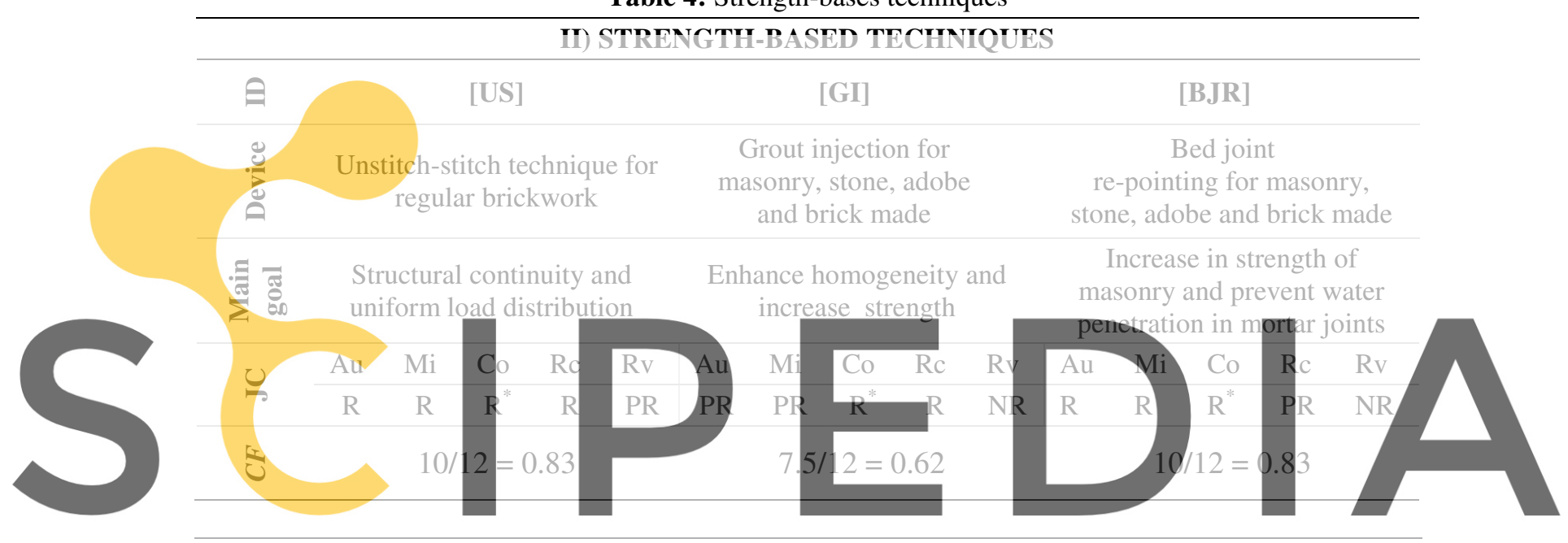

Register for frềe at https//WWWW.scipedia.com to download the version without the watermark

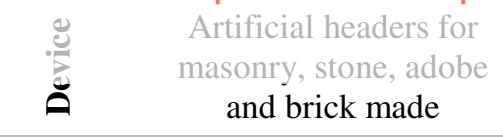
Jacketing of masonry with
steel or CFRP or inorganic matrix Confinement of columns
and pillars with composite
or steel materials

\begin{tabular}{|c|c|c|c|c|c|c|c|c|c|c|c|c|c|c|c|}
\hline 疍 & & $\begin{array}{l}\text { ease } \\
\text { onry } \\
\text { ehavi }\end{array}$ & $\begin{array}{l}\text { ono } \\
\text { anel } \\
r \text { of }\end{array}$ & $\begin{array}{l}\text { hicit } \\
\text { ad gl } \\
\text { uctu }\end{array}$ & & & $\begin{array}{l}\text { ase } \\
d \mathrm{~d}\end{array}$ & $\begin{array}{l}\text { reng } \\
\text { tility }\end{array}$ & $\begin{array}{l}\text { cap } \\
\text { wa }\end{array}$ & & $\begin{array}{l}\text { Incr } \\
\text { duct }\end{array}$ & $\begin{array}{l}\text { ase str } \\
\text { ity of }\end{array}$ & $\begin{array}{l}\text { ngth } \\
\text { olum }\end{array}$ & & $\begin{array}{l}\text { and } \\
\text { jillar }\end{array}$ \\
\hline \multirow[b]{2}{*}{$\stackrel{\cup}{\varrho}$} & $\mathrm{Au}$ & $\mathrm{Mi}$ & $\mathrm{Co}$ & $\mathrm{Rc}$ & $\mathrm{Rv}$ & $\mathrm{Au}$ & $\mathrm{Mi}$ & $\mathrm{Co}$ & $\mathrm{Rc}$ & $\mathrm{Rv}$ & $\mathrm{Au}$ & $\mathrm{Mi}$ & $\mathrm{Co}$ & $\mathrm{Rc}$ & $\mathrm{Rv}$ \\
\hline & NR & PR & $\mathrm{R}$ & $\mathrm{R}$ & PR & PR & PR & PR & $\mathrm{R}$ & PR & NR & $\begin{array}{l}\mathrm{PR}- \\
\mathrm{R} * *\end{array}$ & $\mathrm{R}$ & $\mathrm{R}$ & $\begin{array}{l}\text { PR- } \\
\mathrm{R} * *\end{array}$ \\
\hline 它 & \multicolumn{5}{|c|}{$7.5 / 12=0.62$} & \multicolumn{5}{|c|}{$7 / 12=0.58$} & \multicolumn{5}{|c|}{$10 / 12=0.83$} \\
\hline
\end{tabular}

* The use of materials with same shape, dimensions, stiffness and strength and compatibles from the chemical, physical and mechanical point of view is implied.** The judgment depends on the used materials.

\section{APPLICATION OF IQI METHOD TO TWO CASE STUDIES}

In order to further validate the IQI method to assess the quality of structural rehabilitation interventions in light of ICOMOS principles, two case studies have been identified. Both structures have historical and monumental value, are constituted of unreinforced masonry 
walls, and are located in a highly seismic contest. For both monuments structural characterization and seismic performance have been widely studied. Thus, the reinforcement interventions of San Francisco church, the oldest ancient monument in Santiago Chile [16], and Basilica del Salvador, neo-gothic architecture in Santiago Chile [17], are analyzed through the IQI method. A description of the application of the method on the two case studies is provided below:

(i) Tie-rods [TR], to contain the arch thrust of Basilica del Salvador external gallery.

The use of [TR] for reinforcing URM structures is a traditional solution compatible with conservation principles, as shown by the conservation factor value, $\mathrm{CF}=\sum_{k=1}^{N} \hat{\gamma}_{\boldsymbol{P I}_{\boldsymbol{k}}}=0.91$, in Table3. Overall ICOMOS principles (Min, Co, Rec and Rev) are achieved with total respect, with exception of $\mathrm{Au}$, partially respected.

In the case of the Basilica del Salvador, the introduction of TRs would effectively counteract the activation of overturning mechanisms involving the outer walls of the external gallery (OWs) in Fig.1. As suggest in Section2, safety indexes of structure after $\left(I_{S 2}\right)$ and before $\left(I_{S I}\right)$ a stability-based intervention shall be calculated through the kinematic approach of limit analysis within a macro-element framework to obtain the safety factor $\Delta_{I s}$, (Equ.2). $I_{S 2}$ and $I_{S I}$ are given by the ratio between the spectral seismic acceleration, $\mathrm{a}_{0}^{*}$, and seismic demand, $D_{a i}$. The spectral seismic acceleration is evaluated according to the codified procedures defined in [12]:
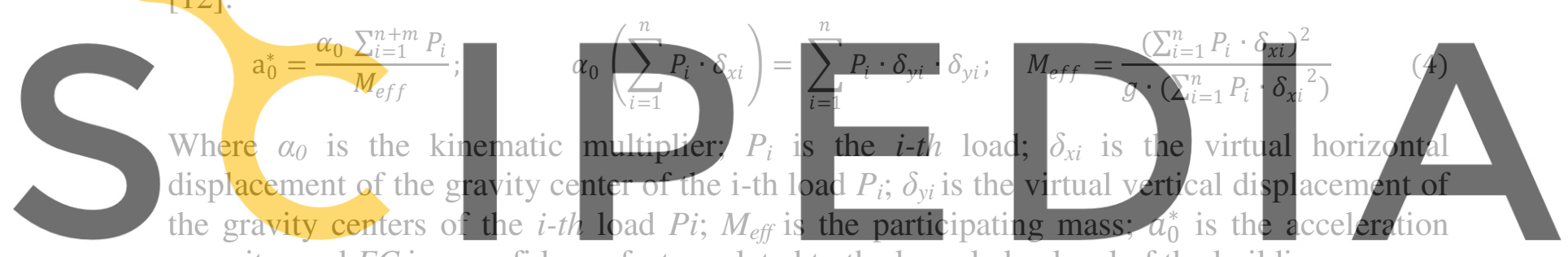

capacity; and FC is a confidence factor-related to the knowledge level of the building.

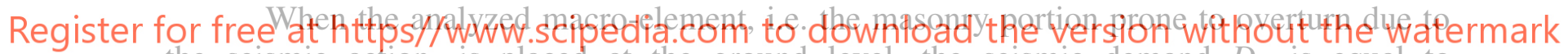

the seismic action, is placed at the ground level, the seismic demand $D_{a i}$ is equal to $D_{a i}=D_{a g}=a_{g}\left(P_{V R}\right) S q$, where $a_{g}\left(P_{V R}\right)$ is the peak ground acceleration with an exceeding probability of $10 \%$ in 50 years; $S$, the sub-soil factor; and $q$, the behavior factor to account for energy dissipation capacity of the unreiforced masonry structure, equal to 1.5 according to[13]. If the macro-element is placed higher than ground level, the seismic demand $D_{a i}=D_{a l}=S_{e}\left(T_{1}\right) \Psi(Z) \gamma$, where $\mathrm{S}_{\mathrm{e}}\left(\mathrm{T}_{1}\right)$ is a design spectrum acceleration with respect to the first vibration period of the macro-block $\mathrm{T}_{1}$, being $\mathrm{T}_{1}=0.05 \mathrm{H}^{3 / 4}[13] ; \psi(z)=Z / H$ is a function depending on the height from the foundation of the centroid of the weight forces applied on the macro-element, $Z$, on the total height of the building from the foundation, $H$, and on $\gamma=3 N /(2 N+1)$, which corresponds to a modal participation coefficient, depending on $\mathrm{N}$ number of floors. Considering the structure before the intervention, the kinematic multiplier of the horizontal equivalent forces producing the activation of the mechanisms, $\alpha_{0}$, is calculated equal to 0.112 and the corresponding spectral acceleration $\mathrm{a}_{0}{ }^{*}$ equal to 0.815 $\mathrm{m} / \mathrm{s}^{2}[17]$.

Table 5: Tie-rod device to prevent the out-of-plane (OOP) mechanism of external gallery walls (OW) of Basilica del Salvador: $a_{0}{ }_{1}{ }_{1}$ and $a_{0}{ }_{2}$ are the mechanism activation accelerations before and after TR intervention; 
$I s_{1}$ and $I s_{2}$ are the safety indexes before and after TR intervention; $\sum_{k=1}^{N} \hat{\gamma}_{\boldsymbol{P I}}$ is the conservation factor; $\Delta_{s}$ is the safety factor; IQI index is the intervention quality intervention index; and CL is the conformity level

\begin{tabular}{ccccccccc}
\hline $\begin{array}{c}\text { Macro-elem.ID } \\
\text { Mech. ID }\end{array}$ & $\begin{array}{c}a_{0}^{*}{ }^{*} \\
{\left[\mathrm{~m} / \mathrm{s}^{2}\right]}\end{array}$ & $\begin{array}{c}a_{0}{ }^{2}{ }^{2} \\
{\left[\mathrm{~m} / \mathrm{s}^{2}\right]}\end{array}$ & $\begin{array}{c}I s_{1} \\
{[-]}\end{array}$ & $\begin{array}{c}I s_{2} \\
{[-]}\end{array}$ & $\begin{array}{c}C F \\
{[-]}\end{array}$ & $\begin{array}{c}\Delta_{s} \\
{[-]}\end{array}$ & $\begin{array}{c}\text { IQI index } \\
{[-]}\end{array}$ & CL \\
\hline OW-OOP & 0.815 & 2.61 & 0.31 & 1 & 0.92 & 0.69 & 0.63 & B \\
\hline
\end{tabular}

Figure 1: External gallery walls of Basilica del Salvador: (a) Tie-rods device to prevent the OOP mechanism,

(b) collapse of external gallery pillars, and (c) deep crack in the arches and vaults.

With the aim of averting the triggering out-of-plane failures of OW macro-blocks, TR introduction is proposed, imposing a ${ }^{*}$ equal to the Demand Acceleration at ground level $\left(D_{a g}=2.61 \mathrm{~m} / \mathrm{s}^{2}\right)$. Considering a circtiar section of tie (length $5.91 \mathrm{~m}$, diameter $22 \mathrm{~mm}$ ), square anchor $(50 \times 50 \mathrm{~cm}$, thickness $20 \mathrm{~mm})$, $E=2100000 \mathrm{daN} / \mathrm{cm}^{2}$ specific weight equal to $\gamma_{s}=7850 \mathrm{daN} / \mathrm{m}^{3}$ ) the is equal to $\alpha_{0,2}=0.359$, considering the tie stres $344 \mathrm{kN}, 86.2 \mathrm{kN}$ ), where $T_{t}$ is the failure mech

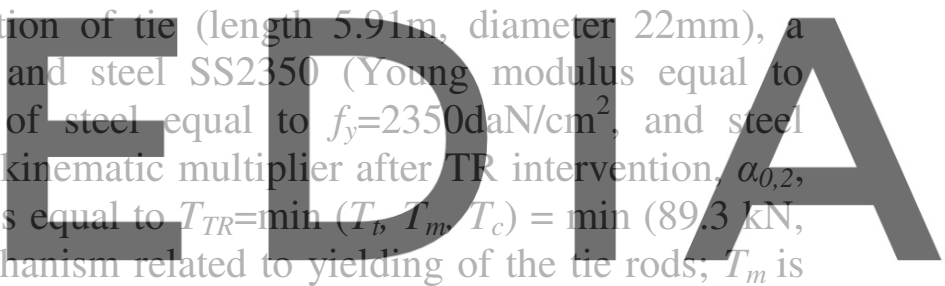
the failure mechanism related to punching of masonry in the anchorage area; and $T_{c}$ is the

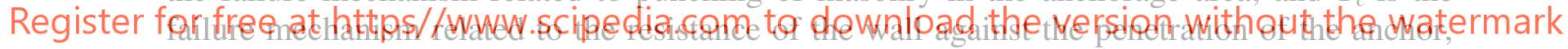

due to excess [15]. The comparative analysis of the current state and the state after the retrofitting intervention (Table5) shows a significant improvement of acceleration capacity of the OOP mechanism of OW. This improvement leads to a satisfactory safety assessment, i.e. safety index after the intervention $I_{s 2}=1$. According to Equ.1, the IQI index for the analyzed intervention is equal to 0.63 , leading to an intervention conformity level type " $\mathrm{B}$ ".

(ii) Buttresses [BT], to improve the out-of-plane stability of San Francisco's transept wall. Historically, masonry buttresses were part of the original construction and performed very efficiently during seismic motion. This device increases the wall section and prevents out-ofplane failures providing resistance to lateral thrusts. The BT strengthening efficiency depends on good interlocking between the original and new structure, and mechanical compatibility concerning strength and stiffness of materials employed. Table3 shows that the use of EN-BT as a seismic device in masonry structures guarantees respect for all conservation principles (R) with the exception of authenticity. The EN-BT intervention determines the alteration of original static and dynamic behavior, not respecting the Au principle. 
As seen in [16], currently the most vulnerable macro-element in the San Francisco church was the transverse arcades of the transept walls (TA). From the historiographical analysis of this structure [16] it emerged that at the beginning of the $20^{\text {th }}$ century the buttresses in correspondence of transept walls and aisles were cut.

Thus, with the aim of averting the triggering of OOP failures of the macro-element and in-plane behavior of the transverse arcade, the introduction of buttresses was proposed(Fig.2) according to the specifications provided in the Guidelines for wall construction with buttresses and pilasters [14]: the buttress thickness must be equal or greater than the wall thickness $\left(\mathrm{t}_{\mathrm{wall}}\right)$; the length of buttress must be equal or larger than $3 \mathrm{t}_{\text {wall }}$; the length (L) between two buttresses must be $L \leq 10 t_{\text {wall }}$ and $L \leq 64 t_{\text {wall }}^{2} / h$, where $h$ is the height of reinforced wall. Considering a shape coherent with the colonial architectural style (a thickness of $1 \mathrm{mx} 1 \mathrm{~m}$, with the same masonry brickwork and mechanical, chemical and physical features of brick and mortar compatible with the original), the current condition of the TA macroelement and the improvement in its the seismic behavior due to the BT device are assessed through LKA analysis (Equ.4) for the northern and southern transept walls. Comparative analyses of the current state and the reinforced state (Table6) show an increase in the safety index (respectively equal to $68 \%$ and $75 \%$ ). These improvements lead to an IQI equal to 0.68 and 0.75 respectively, and an intervention conformity level type "B".
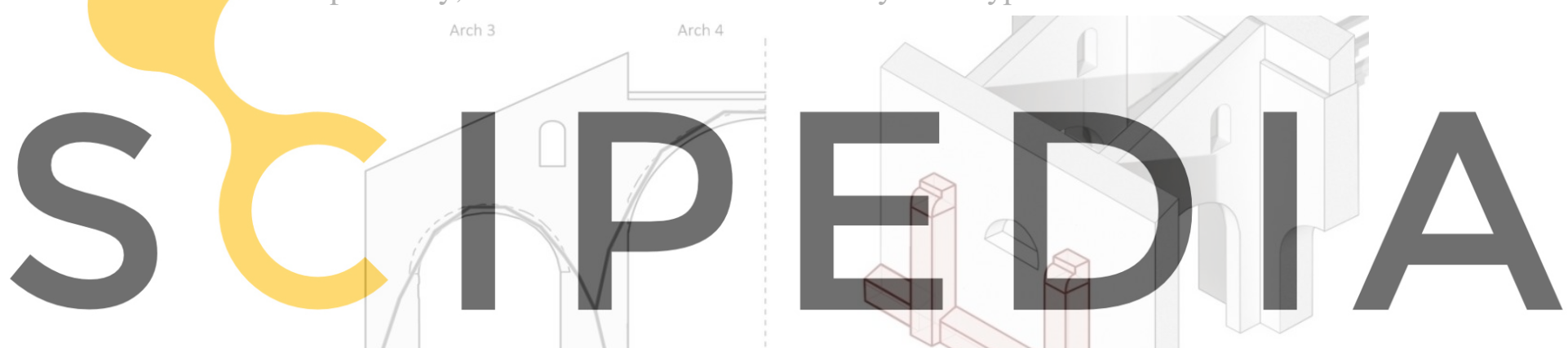

\section{Register for free at²htps//www.scipedia.com to download the version without the watermark}

Figure 2: (a) Thrust line for transverse arcades of transept walls and (b) Buttress device to improve the OOP stability of San Francisco's transept wall.

Table 6: Buttress device to prevent the out-of-plane (OOP) mechanism of transept walls (TR) of San Francisco church: $a_{0}{ }_{1}{ }_{1}$ and $a_{0}{ }_{2}$ are the mechanism activation accelerations before and after BR intervention; $I s_{1}$ and $I s_{2}$ are the safety indexes before and after BR intervention; $C F$ is the conservation factor; $\Delta_{s}$ is the safety factor; IQI index is the intervention quality intervention index; and CL is the conformity level.

\begin{tabular}{ccccccccc}
\hline $\begin{array}{c}\text { Macro-elem. ID } \\
\text { Mech. ID }\end{array}$ & $\begin{array}{c}a_{0}{ }^{*}{ }^{2} \\
{\left[\mathrm{~m} / \mathrm{s}^{2}\right]}\end{array}$ & $\begin{array}{c}a_{0}{ }^{*}{ }^{2} \\
{\left[\mathrm{~m} / \mathrm{s}^{2}\right]}\end{array}$ & $\begin{array}{c}I s_{1} \\
{[-]}\end{array}$ & $\begin{array}{c}I s_{2} \\
{[-]}\end{array}$ & $\begin{array}{c}C F \\
{[-]}\end{array}$ & $\begin{array}{c}\Delta_{s} \\
{[-]}\end{array}$ & $\begin{array}{c}\text { IQI index } \\
{[-]}\end{array}$ & $\mathrm{CL}$ \\
\hline NTA-OOP & 0.866 & 2.34 & 0.33 & 1.01 & 0.83 & 0.68 & 0.57 & $\mathbf{B}$ \\
\hline STA-OOP & 1.03 & 2.63 & 0.39 & 1.14 & 0.83 & 0.75 & 0.63 & $\mathbf{B}$ \\
\hline
\end{tabular}

\section{CONCLUSIONS}

In this paper, a preliminary proposal to introduce evaluation criteria for the reinforcement interventions in relation to the level of compatibility with the conservation principles was 
provided. In order to define the assessment methodology, the conservation ICOMOS principles have been reinterpreted in a purely structural manner considering the impact that a specific retrofit intervention has on the church from a conservation point of view.

The degree of agreement between each retrofit technique and conservation principles has been evaluated through judgement categories (respect, partially respect, and not respect), andthen trasformed into scores. These scores allow to assign a weight relative to the degree of importance that each principle, interpreted in structural terms, assumes in the evaluation procedure. In particular, the respect for compatibility and minimum intervention principles have been assessed as being more significant thanreversibility and recognition.

The describedmethod represents a preliminary proposal that should be better specified in future works, considering further factors influencing the choice of intervention, such as for example: the required safety levels, the state of conservation of the asset, the symbolic importance and the social value, the costs and the duration of the intervention. Moreover, the method applied here to the Chilean context, must be statistically validated for its application to a wider range of construction contexts. The two case studies have been identified in order to evaluate IQI method, considering specific intervention proposals, such as tie-rods for Basilica del Salvador arches and buttress device to improve the out-of-plane stability of San Francisco transept wall.

Generally, the proposed stability-based techniques arise from the rediscovery of traditional earthquake-resistant practices of Chilean constructive culture (extensively documented in [5], [6] and [17]), while the strength-based techniques arise from the use of modern retrofit strategies.

The obtained results show that the rediscovery of traditional earthquake resistant practices, together with the use of modern retrofit strategies, allow preserving and reinforcing the built heritage without harming its identity. In fact, the application of the IQI method leads to very high values of conservation factor for the stability-based techniques $\left(\mathrm{CF}=\sum_{k=1}^{N} \hat{\gamma}_{\boldsymbol{P I}_{\boldsymbol{k}}}=0.83\right.$ 0.91), while it leads to lower values and partial assessment relative to the respect of conservation principles for the strength-based techniques $\left(\mathrm{CF}=\sum_{k=1}^{N} \hat{\gamma}_{\boldsymbol{P}_{\boldsymbol{k}}}=0.58-0.83\right)$.

Acknowledgements. This work was supported by the Research Center for Integrated Disaster Risk Management (CIGIDEN), ANID/FONDAP/15110017, and by the SIBER-RISK Regular Fondecyt project CONICYT/FONDECYT/1170836.

\section{REFERENCES}

[1] Cracow Charter, 2000. Signed by representatives of conservation institutions, Proc Int. Conf. On Conservation, Krakow 2000, Krakow, 191-193.

[2] Venice Charter, 1964. International charter for the conservation and restoration of monuments and sites, Proc., 2nd Int. Congress of Architects and Technicians of Historic Monuments, Venice, Italy.

[3] Spence R, D'Ayala D (1999) Damage assessment and analysis of the 1997 UmbriaMarche earthquakes. Struct Eng Int J Int Assoc Bridge Struct Eng 9(3):229-233

[4] Cancino C (2010) Damage assessment of historic earthen sites after the 2007 earthquake in Peru. Adv Mater Res 133-134:665-670 
[5] Wilkinson S, Grant D, Williams E, Paganoni S, Fraser S, Boon D, Mason A, Free (2013). Observation and implications of damage from the magnitude Mw 6.3 Christchurch, New Zealand earthquake of 22 February 2011. Bull Earthq Eng 13(1):1-35

[6] D'Ayala, D. (2014). Conservation principles and performance based strengthening of heritage buildings in post-event reconstruction. In Perspectives on European Earthquake Engineering and Seismology (pp. 489-514). Springer, Cham

[7] Palazzi, N. C., Rovero, L., De La Llera, J. C., Sandoval, C. (2019). Preliminary Assessment on Seismic Vulnerability of Masonry Churches in Central Chile. International Journal of Architectural Heritage, 1-20.

[8] Palazzi, N. C., Favier, P., Rovero, L., Sandoval, C., \& de la Llera, J. C. (2020). Seismic damage and fragility assessment of ancient masonry churches located in central Chile. Bulletin of Earthquake Engineering, 1-25.

[9] SESOC (2013) Building seismic performance. Submission to the Ministry of Business, Innovation and Employment 8 March 2013.

[10] Masonry Standards Joint Committee, (1999). Building Code Requirements for Masonry Structures, ACI-530-99/ASCE 5-99/TMS 402-99, American Concrete Institute, American Society of Civil Engineers and Masonry Society, Detroit, New York, Boulder.

[11] E.080, (2017). Ministerio de Vivienda, Construcción y Saneamiento. Diseño y construcción con tierra reforzada. Lima, Perú.

[12] Eurocode 8, (2004). Design of structures for earthquake resistance - Part 1: General rules, seismic actions, and rules for buildings (EN 1998-1), European Committee of Standardization. Brussels, Belgium; 2004.

[13] MIT, (2008), Norme Tecniche per le Costruzioni. DM 14 gennaio 2008, Gazzetta Ufficiale, n. 29 del 4 febbraio 2008, Istituto Poligrafico e Zecca dello Stato, Roma.

[14] Circolare n. 26/2010 (2010) Linee Guida per la valutazione e riduzione del rischio sismico del patrimonio culturale, Prot. 10953 del 2 dicembre 2010.

[15] INN, 2013. Estructuras -Intervención de construcciones patrimoniales de tierra crudaRequisitos del Proyecto Estructural. Santiago, Chile NCh3332.Of2013.

[16] Arya, A. S., Boen, T., \& Ishiyama, Y. (2014). Guidelines for earthquake resistant nonengineered construction. UNESCO.

[17] International Council on Monuments and Sites (ICOMOS) Principles for the analysis, conservation and structural restoration of architectural heritage (2003).

[18] Jorquera, N., Misseri, G., Palazzi, N., Rovero, L. and Tonietti, U. (2017). Structural characterization and seismic performance of San Francisco church, the most ancient monument in Santiago, Chile. Intern Jour of Archit Her11(8),1061-1085.

[19] Palazzi, N.C., Rovero, L., Tonietti, U., de la Llera, J.C., Sandoval, C. (2018a). Kinematic limit analysis of Basilica del Salvador, a significant example of the neogothic architecture in Santiago, Chile. In 16th European Conference on Earthquake Engineering, Thessalonica, Greece 18-21 june 2018.

[20] Petzet M. (2004). Principles of preservation: an introduction to the international charters for conservation and restoration 40 years after the Venice Charter

[21] Giaretton, M., Dizhur, D., da Porto, F., \& Ingham, J. (2016). Seismic assessment and improvement of unreinforced stone masonry buildings: literature review and application to New Zealand.". Bulletin of the New Zealand Society for Earthquake Engineering, 49(2). 